\title{
Reducing carbon footprint of deep-sea oil and gas field exploitation by optimization for Floating Production Storage and Offloading
}

Zhuochao Li ${ }^{1+}$ Haoran Zhang ${ }^{*}, 2 \quad$ Jing Meng ${ }^{3}$ Yin Long ${ }^{* *, 4}$ Yamin Yan ${ }^{1}$ Meixuan Li $^{1}$ Zhongliang Huang ${ }^{5}$ Yongtu Liang ${ }^{1}$

1 Beijing Key Laboratory of Urban Oil and Gas Distribution Technology, China University of Petroleum-Beijing, Fuxue Road No. 18, Changping District, Beijing 102249, China;

2 Center for Spatial Information Science, The University of Tokyo, 5-1-5 Kashiwanoha, Kashiwa, Chiba 277-8563, Japan;

3 The Bartlett School of Construction and Project Management, University College London, London WC1E 7HB, UK;

4 Department of Environment Systems, Graduate School of Frontier Sciences, The University of Tokyo, 5-1-5 Kashiwanoha, Kashiwa-shi, Chiba 277-8563, Japan;

5 CNPC offshore engineering company limited, Fenghe Masion, Taiyanggong South Street No. 23, Chaoyang District, Beijing 100028, China.

Corresponding author: E-mail address: zhang_ronan@csis.u-tokyo.ac.jp (H. Zhang); long@globalenv.k.u-tokyo.ac.jp (Y. Long)

\begin{abstract}
Deep-sea oil and gas fields are acting as a vital role by providing substantial oil and gas resource, and Floating Production Storage and Offloading is an indispensable tool for the development of offshore oil and gas fields effectively. Here, Life Cycle Assessment is applied to evaluate environmental loads in the whole life cycle of the deep-sea oil and gas production. This paper explores the carbon footprint of Floating Production Storage and Offloading as the time axis. It is found that Floating Production Storage and Offloading is a conceptual product at the design stage and does not generate carbon emission, while the operational stage releases considerable emission by the fuel combustion process, accounting for $88.2 \%$ of the entire life cycle. To decrease this part of carbon emission, distributed energy system is considered as a promising choice because it integrates different energy resources and provides an economic and environmental energy allocation scheme to meet the energy demand. For the operation stage, this paper establishes a Multi-objective Mathematical Programming model to determine the selection and capacity of facilities with minimum annual total cost and carbon emissions by considering the energy balance and technical constraints. The model is validated by an example and solved by the weight method. According to designer's demand, distributed energy system can optimize economic objectives in a maximum range of $14.6 \%$, and a maximum emission reduction of $4.53 \%$ can be expected compared with the traditional scheme. Sensitivity analysis shows that cost is more sensitive to natural gas price.
\end{abstract}

Keywords: Carbon footprint; Distributed energy system; Life Cycle Assessment; Multiobjective mathematical programming; Floating Production Storage and Offloading

\section{Introduction}




\subsection{Related work}

Floating Production Storage and Offloading (FPSO) is characterized by high adaptability, low cost, high reliability, and reusability [1]. FPSO has gradually become the mainstream facility for production, processing, storage, and transportation of offshore oil (gas) field. In China, more than $70 \%$ of national offshore oil production capacity is supported by FPSO; its design life is generally around 20 to 30 years [2]. With the current globalization of environmental protection and its urgency, the shipbuilding industry as a whole would bear more environmental responsibilities. According to the assessment report of the United Nations Intergovernmental Panel on Climate Change (IPCC), the total global greenhouse gas emissions by 2050 should be reduced by $50-85 \%$ compared with the current level in order to achieve global temperature stability within $2{ }^{\circ} \mathrm{C}$ higher than in the pre-industrial era [3]. In recent years, with the development of large-scale ships and the increase in the number of ships, the greenhouse gas emissions of the shipping industry have risen sharply. It can be seen from the IMO study that the total emissions of the shipping industry in 2010 were 1.046 billion tons, accounting for $3.3 \%$ of the total global carbon emissions. The growth of greenhouse gas emissions from shipping is closely related to the volume of the shipping trade. With the increase in world trade, the emissions from the shipping industry would increase by $150-250 \%$ by 2050 , accounting for $12-18 \%$ of the global allowable emissions. However, all industries need to set an emission reduction goal to achieve the IPCC goal of reducing global greenhouse gas emissions to $50-85 \%$ of the current level by 2050 . For the shipping industry, the carbon emissions of the shipping industry should not exceed $15-50 \%$ of the current level by 2050 to meet the global greenhouse gas emission reduction requirements [4]. China promises to peak $\mathrm{CO}_{2}$ emissions by 2030 [5]. Nowadays, international competition is becoming increasingly intense with the promotion of low-carbon technology. A green revolution is launched in the field of shipbuilding, shipping, and shipbreaking industries. Competition in the shipping industry would be not only performed in terms of product performance, service quality, and marketing means but also extended to environmental protection. Therefore, how to improve production efficiency and reduce its environmental burden has attracted more attention in China recently.

Many researchers have conducted various researches on carbon emission. For the first time, Jia Shuo Li [6] understood carbon emissions from the perspective of income. He also proposed that more attention should be paid to reduce carbon emissions from the perspectives of demand and supply. Besides, Chen et al. [7] provided a new aspect for understanding the global energy system by using the environmentally extended input-output analysis (EEIOA). Fang Kai [8] put forward a scientific economic aggregate allocation scheme, providing a basis for independent emission reduction work. Fang Kai [9] developed a set of extended STIRPAT models that can predict and evaluate the trajectory of carbon emissions. Hui Qiao [10] believed that renewable energy such as hydropower, wind energy, and solar energy must be developed in developing regions in order to reduce energy consumption. Hui Qiao [11] pointed out that economic growth only has a positive impact on carbon dioxide emissions in developing countries. Globally, Kangyin Dong [12] believed that economic growth has the greatest impact on carbon dioxide emissions.

As an efficient tool of environmental management and preventive means of environmental 
protection, Life Cycle Assessment (LCA) has formed ISO14040-14043 standard series; it has become an important means of product development, environmental certification, and trade barrier avoidance. LCA is a widely used method to analyze building carbon emissions in recent years. Biology holds that the life cycle is the observation and description of the cycle of birth, growth, maturity, decline, and death of organisms; besides, it is also the characteristics of different stages [13]. During recent decades, the thinking of life cycling is widely adopted in environmental impact evaluation. The first life cycle theory of Dean [14] aims to study the market strategy and positioning of products. In the "Life cycle evaluation of ship transportation" project hosted by the Aalesund Institute in Norway, the simplified LCA method is applied to the M/V Color festival; the existing tools (Eco-indicator95) are used for the full life cycle assessment of a ship. The project demonstrated that the LCA method applies to the ship's full life-cycle environmental impact assessment [15]. In the project of "tool for energy efficient ships design" hosted by the European Union, the LCA method was applied to the ship design process; corresponding calculation software was developed to help designers to reduce the energy consumption and emissions of major pollutants in different life cycle stages. It is evaluated by different characterizations and methods. This tool is mainly used in the designs of passenger ferries, container ships, and fishing boats [16]. A detailed inventory survey of the ship's construction phase, operation phase, and dismantling phase was conducted by the National Maritime Research Institute of Japan. The $\mathrm{CO}_{2}$ emissions of the three life cycle stages of the 85000DWT tanker were counted and the method of inventory analysis for each stage of the ship was developed [17]. As a system product, the ship has the characteristics of design and demonstration of new products, engineering development and progression, production of shipyards, commissioning, and final scrapping. The life cycle of the product has been evolved in the process of market development, mainly in the stages of introduction, growth, maturity, and decline [18]. The life cycle of the ship from the design stage was discussed by Sulaiman et al. [19]. They believed that the success or failure of the ship's life cycle is determined as $90 \%$ by the design stage, which further expands the choice of marine materials and equipment. Okasha et al. [20] took the ship life cycle as a clue and used a data structure health monitoring method to analyze the uncertainty of ship structure. The key technologies of information technology management, agile manufacturing mode, and hull management of ship construction were discussed from the construction stage of the ship life cycle when Frangopol et al. [21] used a probability method to analyze the reliability, fatigue, and material deterioration of ship structure. According to the theory of ship life cycle, Kumakura et al. [22] illustrated that the cost of raw materials for ships reached $50 \sim 60 \%$ of the total construction cost. Misra et al. [23] believed that the impact of the design stage on the process of ship construction, operation, and disassembly should be considered in the sustainable development of the ship's life cycle. Erik et al. [24] proposed that ship design could be optimized using the concept of green design to reduce ship carbon footprint; besides, the factors of ship carbon emissions should be fully considered in the design. Based on the fuel consumption per unit of the ship from 1995 to 2001, Eyring et al. [25] established a carbon footprint model for the whole life cycle from the perspective of fuel consumption. The life cycle assessment method has been used by many researchers to analyze ships. However, up to now, FPSO for the whole life cycle has not been evaluated; the design and operation strategy of ships based on evaluation has not been optimized. As the main offshore oil and gas production facility, FPSO consumes a lot of energy 
while guaranteeing offshore oil and gas production. Many researches have been carried out in the following two directions in order to alleviate the loss caused by energy waste.

The first possibility aims at minimizing the system's energy demand, continuously improving equipment efficiency and reducing unnecessary energy losses [26]. Ali Allahyarzadeh-Bidgoli et al. [27] took the minimum total fuel consumption of FPSO as the objective function, optimized seven parameters related to equipment working pressure, and used the genetic algorithm to achieve the results, illustrating that fuel consumption, power consumption of the power plant, and recovery rate of light components of the optimized scheme were improved compared to the conventional scheme. J. S. Li [28] proposed an optimal energy saving strategy based on comprehensive information to reduce total energy consumption. Moreover, the exergy efficiency of each equipment in the petroleum separation process of offshore platforms and the overall performance of the platforms were assessed by Oliveira Jr et al. [29]. Nguyen et al. [30] analyzed the exergy of two schemes that deviate obviously from the optimal operating conditions and simulated them with HYSYS software. The results showed that there is a lot of space for energy saving in the gas treatment process; the idea of integrating as much energy as possible was put forward. Besides, the valve of injection well was replaced by Zhao [31] with a sanctionable jet pump; it was tested by establishing a three-dimensional model. According to data analysis, the energy consumption of offshore water injection development could be significantly reduced by the jet pump water injection system compared to the offshore water injection system with a throttle valve. Voldsund et al. [32] have performed exergy analysis and comparison of four offshore platforms. The results demonstrated that exergy damage mainly occurs in the natural gas treatment and compression parts. It is also pointed out in this paper that it would be more effective to improve exergy efficiency in the gas compression system and recovery system. Nguyen et al. [33] used the method of exergy analysis to compare the three typical stages of the oil field, concluding that the efficiency is quite low in chemical energy consumption and heat energy transfer. The pinch-based method was employed by Abdul et al. [34] to reduce carbon dioxide emissions and optimize plant energy systems. Gallo et al. [35] used the second law of thermodynamics to consider the various equipment in the oil and gas water treatment process and evaluated the compression system. He suggested that there are various opportunities for energy improvement and utilization in the irreversible process. Nguyen et al. [26] believed that the maximum improvement of energysaving is related to capacity. These researchers studied the energy consumption requirements of offshore platforms and found that there is a lot of space for energy consumption improvement in natural gas compression. Some researchers have optimized the energy consumption scheme and obtained good results. However, the energy consumption of specific FPSO was not optimized in the studies mentioned above. There are some limitations because they only considered the indicators of energy consumption, without coupling the economy with the environment.

The second possibility is to make it more efficient in the transformation between energy [36]. Replacing gas turbine and boiler with cogeneration equipment is a typical example of this method. Lars O. Nord et al. [37] regarded the combined cycle of offshore oil and gas fields as the useful technology that possesses the advantages of flexibility and efficiency compared with the simple cycle of gas turbines. Pierobon et al. [38] compared the waste heat recovery technologies such as the steam Rankine cycle, the air bottom cycle, and the organic Rankine 
cycle, and established the Multi-objective mathematical programming (MOMP) model to solve this problem. The results showed that carbon dioxide emissions could be effectively reduced by the organic Rankine cycle. At present, most of the researches on waste heat recovery system relating to FPSO are about recovering the waste heat of gas turbine installed on the platform in order to meet the demand for heat energy. Veloso et al. [33] considered the technical and energy constraints of the organic Rankine cycle heat exchanger and established the MOMP model. The results illustrated that the ORC cycle significantly contributed to improving equipment efficiency, reducing energy consumption, and effectively reducing carbon dioxide emissions. The organic Rankine cycle was mainly employed to convert geothermal [32], biomass [41], solar energy [39], and waste heat [42] into thermal energy. Mondejar et al. [43] established the ORC model for waste heat recovery and performed the quasi-steady-state simulation, demonstrating that energy consumption and carbon emissions can be significantly reduced by ORC. Besides, waste heat recovery devices were applied by Suarez et al. [44] to merchant ships; it was found that they have a great effect on reducing carbon emissions. Pierobon et al. [45] used the genetic algorithm to establish a multi-objective model with thermal efficiency, total system volume, and net present value as the objective functions to optimize the organic Rankine cycle. By establishing a simple single-stage cycle and two-stage system model, Walnum et al. [46] concluded that the combined cycle is more efficient than a gas turbine. The above researchers have performed a lot of studies on improving energy conversion efficiency; however, no researcher has combined FPSO with distributed energy systems for research.

This paper aims to solve some problems ignored by the above researches and provide a more reliable and reliable reference for FPSO decision makers. Generally, the research gaps between carbon emissions estimation and energy consumption can be summarized as follows:

(1) There is currently no literature on the full life cycle analysis of FPSO carbon emissions.

(2) The design and operation strategy of a specific FPSO has not been optimized according to its energy demand in the previous references.

(3) Some researchers have evaluated the energy consumption of offshore platforms; however, they only considered the energy consumption indicators and did not consider the coupling of economy and environment; thus, there are some limitations.

(4) Some researchers have performed a lot of researches on improving energy conversion efficiency while no researchers combined the distributed energy system with FPSO for optimization research.

Having reviewed these studies, we can draw a conclusion that it is a more promising option because the economic and environmental optimization of distributed energy systems (DES) is used in conjunction with FPSO.

DES refers to the efficient combined cooling and heating and power system installed on the user side, including the energy generation, energy conversion, and energy output unit [47]. Compared with traditional concentrated and large-scaled energy systems, DES has the characteristics of energy saving, environmental protection, and high safety performance, contributing to alleviating the crisis and achieving sustainable development [40]. Yamin Yan proposed to use a distributed energy system to reduce carbon emissions of buildings [48] and cruise ships [49]. The main functions of FPSO include oil and gas exploitation, oil and gas water separation, crude oil storage and transportation, production assistance system, and public 
system, etc. FPSO needs to be equipped with corresponding living modules because some production facilities need to be operated and maintained by staff; it is integrated with offshore facilities integrating production and living. The energy demand for FPSO includes electricity, heating, and cooling. Electric energy is mainly used to drive compressors, pumps, and other equipment, as well as household electricity. Heat energy is mainly used in oil and gas processing technology and household heating. The demand for cold energy mainly comes from the life module. Gas turbines are widely employed in offshore power plant systems due to the small footprint, lightweight, and the ability to fully utilize the platform's self-produced energy. For the heat demand in production, direct-fired heat medium boilers are usually used to heat the heating equipment; for the heat demand of daily life, direct-fired boilers are also employed to produce steam for heating. In summer, compressed refrigerators are used for cooling the living module. Although its energy supply equipment is constantly updated, there is still room for improvement in the integration of its energy supply system. Simultaneously, the advantages of distributed energy systems are matched with the characteristics of most FPSOs that cannot be connected to conventional energy supply facilities such as power grids. To sum up, those facilities of offshore production and living with the self-generating module and cold or thermal energy requirements would become important application objects of the distributed energy system.

In this paper, environmental loads in the whole life cycle of the deep-sea oil and gas production are evaluated by using Life Cycle Assessment. Besides, the carbon footprint of Floating Production Storage and Offloading as the time axis is explored. It is found that Floating Production Storage and Offloading is a conceptual product at the design stage and does not generate carbon emission, while considerable emissions are released by the fuel combustion process during the operational phase. The distributed energy system is considered as a promising choice to decrease this part of carbon emission because it integrates different energy resources and provides an economic and environmental energy allocation scheme to meet the energy demand. For the operation stage, a Multi-objective Mathematical Programming model is established in this paper to determine the selection and capacity of facilities with minimum annual total cost and carbon emissions by considering the energy balance and technical constraints.

Three assumptions are proposed in this paper.

(1) For the input energy, it is assumed that there is no limitation on the total input.

(2) In the whole life cycle of a ship, railway transportation would produce $\mathrm{CH}_{4}$ and $\mathrm{N}_{2} \mathrm{O}$ during the steel transportation stage of the ship construction stage. These kinds of gases are neglected and only $\mathrm{CO}_{2}$ emission is considered.

(3) FPSO has the capacity of natural gas storage and export, and the surplus natural gas can be exported and sold as FPSO products.

\subsection{Contribution of this work}

(1) For the first time, the FPSO and the distributed energy system are combined; the design and operation strategies of the FPSO are optimized for the specific energy consumption requirements; the Pareto optimal solution is obtained to provide a different reference for designers.

(2) For the first time, Life Cycle Assessment is applied to evaluate environmental loads in 
the whole life cycle of the deep-sea oil and gas production. In this paper, the carbon footprint of Floating Production Storage and Offloading as the time axis is explored.

(3) Considering both economic and environmental objectives, multi-objective mathematical programming for the optimal design of the FPSO energy system is established.

\subsection{Paper organization}

This paper is organized as follows. In the second section, the research methods of this paper are introduced, including the configuration of the energy system and the basic ideas of the optimization model. Then, the concept, meaning, and solution of the mathematical model in this study are described in the third section. Next, an FPSO is taken as an example in the fourth section for detailed discussion and study; the research results are provided; moreover, sensitivity analysis of price fluctuation of crude oil and natural gas is conducted. Finally, the conclusions are drawn and the suggestions are provided in the fifth section.

\section{Methodology}

The concept of FPSO life cycle belongs to time domain and does not describe the specific time. The life activities of FPSO are applied to the time axis to form the time sequence of the FPSO life cycle. The stages of the FPSO life cycle can be divided into design, construction, shipping and disassembly. Fig. 1 shows the life cycle of FPSO.

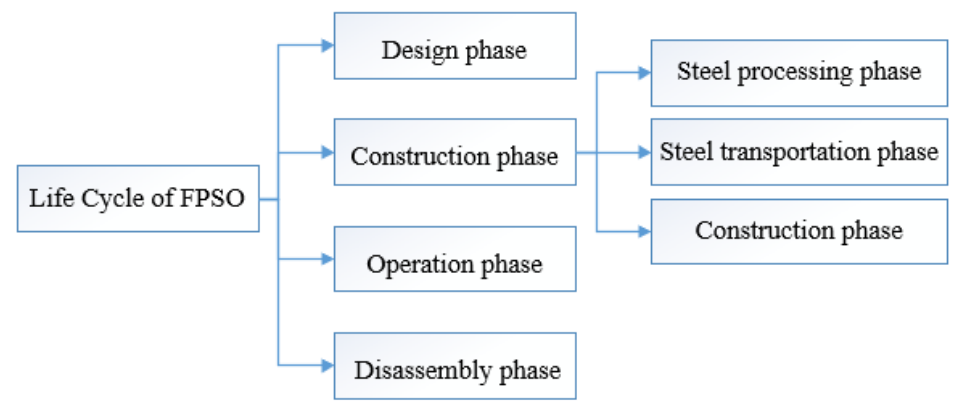

Fig. 1. Four phases of the FPSO life cycle.

\subsection{Energy system configuration}

The design stage is the most initial stage of the FPSO life cycle, which plays a leading role in the life cycle of the FPSO. The design of FPSO determines the technology, economical and safety indicators of FPSO. At the design stage, carbon emissions are mainly come from power consumption and paper consumption when designers work. The $\mathrm{CO}_{2}$ emissions are very tiny. At the same time, the-beginning of FPSO life cycle originates from the design stage. FPSO does not serve as an entity to stay in the design phase and produce economic activity. Therefore, carbon emissions during the design stage are not considered in accounting.

There are two sources of carbon dioxide in construction phase: one is the steel processing and transportation required to build the FPSO, and another is the construction process of FPSO. The $\mathrm{CO}_{2}$ emission from steel manufacturing is mainly the direct emission from each processing procedure and the power consumption during steel processing. Steel is transported by train, and the greenhouse gas is mainly $\mathrm{CO}_{2}$ produced by locomotive combustion of fuel. The $\mathrm{CO}_{2}$ emission in FPSO construction phase is mainly caused by power consuming, steel cutting and steam using during FPSO constructed. 
The $\mathrm{CO}_{2}$ is mainly produced by fuel consumed during FPSO navigation in the FPSO operation phase. The FPSO in the deep sea has power generation system. The main power station provides electric energy for the production and living equipment of the whole project, such as various kind of pump units, daily electricity, crane machine power, crude oil processing and so on. In addition to power stations, thermal stations are built in offshore oil and gas fields. The main equipment of heat station is heat medium boiler, which is responsible for heating crude oil to meet the temperature requirement when crude oil is processed and entering the treatment equipment. It can supply heat to the air conditioning system and FPSO too. To ensure formation pressure, offshore oil and gas fields are also equipped with water injection system. The water injection system includes a water injection pump, drive motor, water injection pipeline, water injection well, water distribution room and various valves. The water injection pump is one of the main energy consuming equipment because of its large flow rate and high outlet pressure. The electric submersible pump is one of the main equipment to extract oil in offshore oilfields. The inlet pressure of fuel gas for gas turbine generators is generally between 2.0 $\mathrm{MPa}$ and 3.0 $\mathrm{MPa}$, so natural gas compressor units are mostly needed to increase pressure of fuel gas to meet the requirements of intake pressure. The offshore oil production platform is an isolated system, which needs a lot of power, heat and cold energy. Generally, the required power is not suitable for external inputting, and it is necessary to use the generator sets to generate electricity. Natural gas and crude oil are the main fuel of gas turbine generating units. A large amount of $\mathrm{CO}_{2}$ is produced during the operation of the above equipment.

In this paper, a DES is established to reduce the carbon emission in the operation phase. Fig. 2 shows the overall structure of DES, including gas boiler (GB), gas turbine (GT), crude oil generator (COG), compressed chiller (CC), absorption chiller (AC), photovoltaic panel (PV), wind turbines (WT), battery (BT), heat storage (HS) and cold storage (CS). Generally, the demand for electricity is generated by generators, and the deficiency can be compensated by installing photovoltaic panels and wind turbines. For providing cooling source, compressed chiller can be used, or absorption chiller that absorbs waste heat from gas boilers can also be used. There are three kinds of heat sources to meet the heating demand: GB, GT and COG. Energy storage equipment plays a significant role in peak shaving.

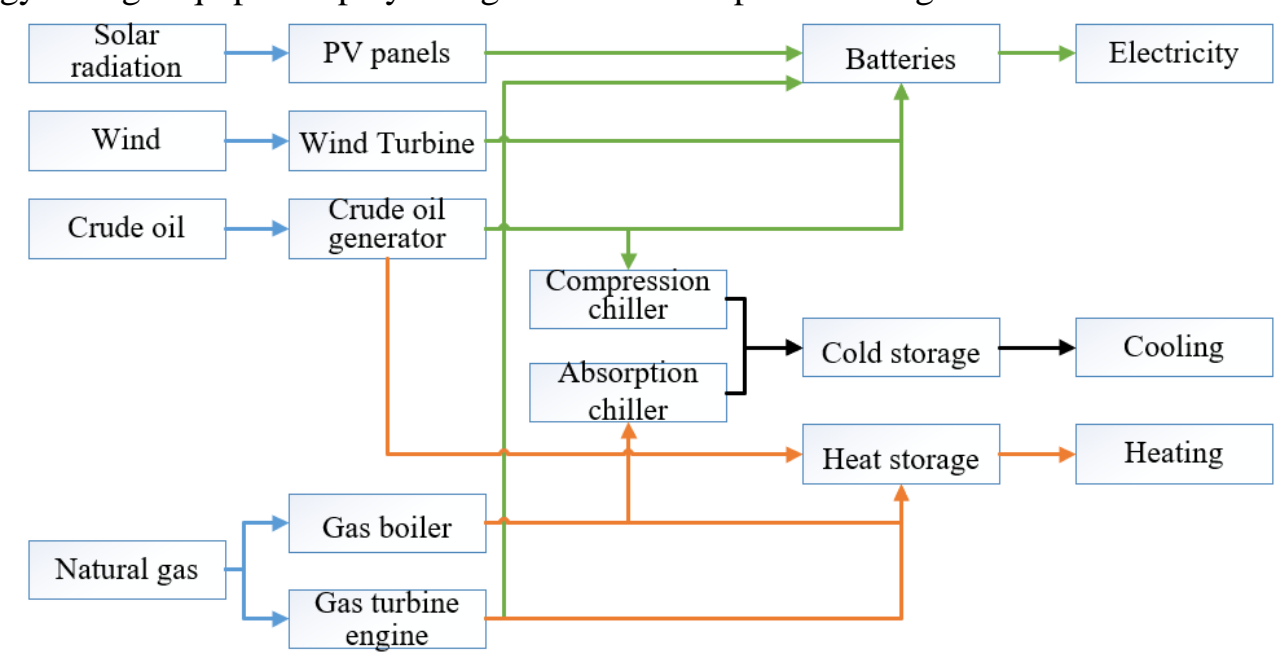

Fig. 2. Structure of DES (distributed energy system) in the FPSO.

The disassembly phase is an inevitable stage. It is an effective measure to recycle resources. The scrapped FPSO is dismantled into steel plates, spare parts and various 
equipment. After testing, the recoverable equipment is confirmed, and the reutilization of resources is completed. The carbon footprint of the FPSO in disassembly phase is mainly caused by steel cutting and power consumption in production.

\subsection{Problem description}

In this paper, the MOMP model is established with the minimum total annual cost and annual carbon emissions as the objective function, considering the energy balance and design constraints. In the optimal problem, three special days are used to represent winter、 summer and midseason. The input parameters of the model are the special 3-day energy consumption data. In addition, the model needs to input energy demand, energy price and technical parameters of various equipment. The decision variables are the capacity of the equipment and the amount of input energy. The MOMP model was integrated by weighting method and solved by MATLAB 2014 b. The design and operation scheme of FPSO under the objective of economic and environmental optimization is obtained. Fig. 3 shows the framework of optimization process.

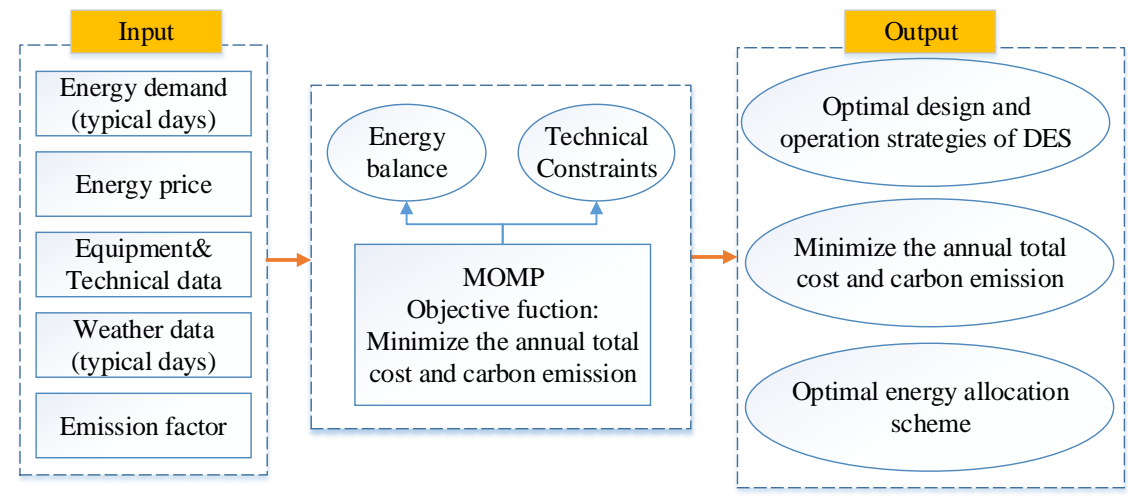

Fig. 3. Multi-objective optimization model includes objective function, input parameters, output parameters and constraints.

\section{Mathematical Model}

Although there are many single-objective or multi-objective optimization models for DES, few people have discussed the optimal design of DES for FPSO.

\subsection{Economic Objective}

The economic goal is to minimize the total annual cost of the FPSO. The total annual cost value $F_{\text {total }}$ includes the investment cost $F_{\text {inv }}$ and operating $\operatorname{cost} F_{\text {ope }}$, which can be described as follows:

$$
\begin{gathered}
F_{\text {total }}=F_{i n v}+F_{\text {ope }} \\
F_{\text {inv }}=\sum_{i}\left(B_{i} E_{i}+W_{i} F_{i}\right) A_{i} \\
F_{\text {ope }}=\sum_{t \in T} \sum_{m \in M} C P_{t, m} P_{t, m} w_{t} \\
H_{i}=\frac{r(r+1)^{L_{i}}}{(r+1)^{L_{i}}-1}
\end{gathered}
$$


In Eq. (2), $I$ is the set of energy allocation equipment; $W_{i}$ represents the capacity of equipment $i ; B_{i}$ is a binary variable, $B_{i}=1$ when the system selects the ith device, $B_{i}=0$ when the system does not select the ith device; $E_{i}$ and $F_{i}$ are two parameters that represent the fixed cost and linear cost of equipment $i ; H_{i}$ is the capital recovery factor of equipment $i, r$ in Eq. (4) is the depreciation rate, and $L t_{i}$ is the life of equipment $i$;

In Eq. (3), $m$ is a type of input energy, including oil and gas; $C P_{t, m}$ represents the consumption of energy $\mathrm{m}$ at the time $t ; P_{t, m}$ is the price of $m ; w_{t}$ represents the number of time steps.

\subsection{Environmental Objective}

The environmental goal is to minimize carbon dioxide emissions.

$$
F_{\text {emission }}=\sum_{n \in N} \sum_{t \in T} \sum_{m \in M} C P_{t, m} E F_{m} w_{t}
$$

Where $E F_{m}$ is the emission factor of the energy type $m$

\subsection{Energy balance constraints}

In this section, energy balance constraints are considered to facilitate the realization of the co-ordination of the supply and demand for electricity, heating, and cooling.

The energy balance constraint mainly indicates that the energy output on the FPSO must be equal to the input during the $t$ period. These include electrical energy balance, cold energy balance, thermal energy balance, and other balances. The energy balance is shown in Eq. (6). On the left-hand side is the sum of PV, wind-driven generator, crude oil generators, battery refresh and combustion turbine; minus the possible power consumption of the compression refrigerator and battery refresh. On the right-hand side is the power demand of FPSO.

$$
\begin{gathered}
n_{P V} W_{P V} I N_{t}^{P V}+n_{W T} W_{W T} I N_{t}^{W T}+n_{C O G, e l e} M_{t, C O G}+n_{G T, e l e} M_{t, G T}-M_{t, C C}+N_{t, B T}^{d i s}-N_{t, B T}^{c h}=D_{t}^{e} \\
\forall t \in T
\end{gathered}
$$

The balance of cold energy is given in Eq. (7): where cooling of compression refrigeration and absorption refrigeration, together with the discharge of cold energy storage facilities, excluding the storage of cold energy storage equipment is the cold energy demand of FPSO.

$$
E E R_{C C} M_{t, C C}+E E R_{A C} M_{t, A C}+N_{t, C S}^{d i s}-N_{t, C S}^{c h}=D_{t}^{c} \quad \forall t \in T
$$

The heat recovered by Gas boiler, combustion turbine, crude oil generators, and the heat release of thermal energy storage device excluding heat storage of steam cooler and thermal energy storage equipment, is the thermal energy demand of FPSO.

$$
\begin{gathered}
n_{G B, \text { heat }}\left(M_{t, G B}-M_{t, A C}\right)+n_{G T, \text { heat }} M_{t, G T}+n_{C O G, \text { heat }} M_{t, C O G}+N_{t, H S}^{d i s}-N_{t, H S}^{c h}=D_{t}^{h} \\
\forall t \in T \\
M_{t, A C} \leq M_{t, G B} \forall t \in T
\end{gathered}
$$

Looking at these equations, $n_{i}$ indicates the efficiency of the equipment $i . E E R_{C C}$ and $E E R_{A C}$ represents the efficiency of the $\mathrm{CC}$ and AC. $M_{t, i}$ is a variable that defines the 
energy input to the equipment $i$ at a time step $t . D_{t}^{e}, D_{t}^{h}$ and $D_{t}^{c}$ are deterministic parameters representing the electrical, heating and cooling demand at the time step $t$, respectively. $N_{t, k}^{c h}$ and $N_{t, k}^{d i s}$ are variables that represent the charging rate and discharging rate of energy storage equipment $\mathrm{k}$ at a time $t$.

For the input energy, assuming that there is no limit on the total amount of input. To ensure the energy input into the specific equipment, the following equation constraints are necessary.

$$
\left\{\begin{array}{l}
M_{t, G B}+M_{t, G T}=C P_{t, \text { gas }} \\
M_{t, C O G}=C P_{t, \text { oil }}
\end{array}\right\} \forall t \in T
$$

Where $C P_{t, m}$ defines the consumption of energy type $m$ at a time step $t$.

Batteries, cold energy and thermal storage facilities are also considered. They are mainly used for storing power, heating, and cooling energy, thereby reducing the capacity of an unnecessary increase of the conversion facility due to the large fluctuation of the energy demand and playing a peak regulation role. The following constraints are required for the description of energy storage facilities. Energy storage facilities only support adjustment of short-term, daily fluctuations but it cannot be used as seasonal storage. Here, the energy storage equipment is set to run one cycle a day. Eq. (11) is suitable for any time except in the first hour of the day. Conversely, Eq. (12) applies to the first hour of the day. In addition, the energy stored by the device in the first hour is equivalent to what is stored at the end of the day.

$$
\begin{gathered}
S_{t, k}=n_{k}^{\text {loss }} S_{t-1, k}+n_{k}^{c h} N_{t, k}^{c h}-N_{t, k}^{d i s} / n_{k}^{c h} \quad \forall n \in N, \forall t \in T \backslash \bar{T}, \forall k \in K \\
S_{t, k}=n_{k}^{\text {loss }} S_{t+23, k}+n_{k}^{c h} N_{t, k}^{c h}-N_{t, k}^{d i s} / n_{k}^{c h} \quad \forall n \in N, \forall t \in \bar{T}, \forall k \in K
\end{gathered}
$$

Where $S_{t, k}$ is a variable that defines the amount of energy stored in the equipment $k$ during the time step $t$. Furthermore, $n_{k}^{\text {loss }}, n_{k}^{c h}$ and $n_{k}^{\text {dis }}$ represent the self-discharge losses, charging efficiency and discharging efficiency of energy storage equipment $k$.

\subsection{Technical constraints}

As long as the equipment is selected, the binary variable $B_{i}$ is equal to 1 . Due to technical constraints, the capacity of the equipment cannot exceed the maximum value $M A X$. It prevents the installation of excessive capacity. MIN ensures that the formula is and remains nonnegative and avoids unnecessary outputs and irrelevant results, which is a minimum value corresponding to $M A X$.

$$
\left(B_{i}-1\right) M A X+M I N \leq W_{i} \leq B_{i} M A X \quad \forall i \in I
$$

Capacity violation cannot occur in the operation process of the energy generation equipment. Similarly, the operating capacity of the energy storage facilities should not exceed the rated capacity at any time.

$$
\begin{gathered}
M_{t, j} \leq W_{j} \quad \forall t \in T, \quad \forall j \in J \\
S_{t, k} \leq W_{k} \quad \forall t \in T, \quad \forall k \in K
\end{gathered}
$$

$J$ is a collection of energy storage equipment.

There is an upper limit for energy storage facilities, PV panels and wind turbines due to 
limited available space in the district.

$$
\begin{gathered}
W_{k} \leq S_{k}^{\max } \quad \forall n \in N, \quad \forall k \in K \\
W_{P V} \leq S_{P V}^{\text {roof }} \\
W_{W T} \leq S_{W T}^{\text {roof }}
\end{gathered}
$$

\subsection{Optimization Method}

The economic objective function and the carbon emission objective function are established in equations (1) and (5) respectively. The problem needs to minimize these two objective functions. To solve this multi-objective optimization problem, a single objective function is used to express the weighted summation of the total economic cost and total carbon emissions. This will result in the production of the minimum value of the single objective function.

$$
F_{o b j}=c w F_{\text {total }}+(1-w) F_{\text {emission }}
$$

Where $\mathrm{c}$ is the scale factor, ensuring that $C_{T O T}$ and $C_{\text {emission }}$ are of the same order of magnitude. Pareto frontier can be found by changing the value of $w$ and letting it change between $0-1$. When $w=1$, the solution with the smallest economic objective can be found. When $w=0$, the solution with the least carbon emission can be found. The above problems are linear, using branching and cutting, which is very effective for MILP.

The weighting method [50] is most widely applied when solving MOMP problems; in essence, it can provide a representative subset of the Pareto set which in most cases is adequate. The example in this paper is solved using the weighting method.

\section{Case Study of FPSO Carbon Footprint}

\subsection{Case object}

The model is applied to an FPSO unit serving in a deep-water field in the central Pacific Ocean. The FPSO is 256 meters long and 45 meters wide. It can accommodate more than 50 staff and weighs 180,000 tons. It runs uninterrupted throughout the year with design life of 25 years.

\subsection{Carbon Footprint of FPSO in the Construction phase}

\subsubsection{Carbon Emissions from Steel Manufacturing for FPSO Construction}

The main raw material for FPSO construction is steel. According to research data on the construction of an FPSO unit, the steel consumption for the construction of a 180,000-ton FPSO unit is about 24,000 tons of $\mathrm{CO}_{2}$. According to the research results of the "Study on the Evaluation of Environment Coordination in the Process of the Production of Iron and Steel Materials[D]" of Zhou Hemin, the $\mathrm{CO}_{2}$ emitted in producing one ton of steel is about 2.786t. This led to the conclusion that the $\mathrm{CO}_{2}$ emission from the construction of an FPSO is 6.6864 million tons. 


\subsubsection{Carbon Emissions from the Transportation of Steel for FPSO Construction}

Railway transportation is considered suitable for steel transportation [52]. According to statistics from the Beijing Railway Administration, the fuel consumption of rail freight locomotives is $22.4 \mathrm{~kg}$ diesel/ $\left(10^{4} \mathrm{t} \cdot \mathrm{km}\right)$. Simultaneously, assuming that the transportation distance is 200 kilometers, the fuel consumption in transporting steel is $29955 \mathrm{~kg}$. From the calorific value of diesel oil published in CHINA ENERGY STATISTICAL YEARBOOK, the calorific value of locomotive fuel consumption is $42.652 \mathrm{MJ} / \mathrm{kg}$. The emission factors of greenhouse gases from rail transport with reference to the corresponding data in the IPCC Guidelines for National Greenhouse Gas Inventories, where the emission coefficient of $\mathrm{CO}_{2}$ is $74100 \mathrm{~kg} / \mathrm{TJ}$, and the calculated carbon emissions are 94.7 tons.

\subsubsection{Carbon Emissions from FPSO Construction}

Carbon emissions from FPSO construction are in three parts: carbon emissions from electricity required for FPSO construction, carbon emissions from steam required for FPSO construction and carbon emissions from steel cutting.

The power consumption of building a 180,000 -ton FPSO is about $1.08 \times 10^{7} \mathrm{kWh}$. According to "Announcement on the publication of emissions factors from the Datum of China's Regional Power Grid" issued by the Environmental Certification Center of the Ministry of Environmental Protection about the $\mathrm{CO}_{2}$ emission factor of North China regional grid of $1.0069 \mathrm{t} / \mathrm{MWh}$, it can be calculated that the $\mathrm{CO}_{2}$ emission caused by power consumption in the construction of FPSO is 10874 tons.

Besides, from the investigation and estimation of similar FPSO construction, the amount of steam required for the construction of a 180,000-ton FPSO is about 4500 tons. It is estimated that the amount of coal consumed to produce these vapors is about 675 tons, and the amount of $\mathrm{CO}_{2}$ discharged from these vapors is estimated to be about 1202 tons.

According to the survey data of the actual FPSO construction, the acetylene gas consumed by cutting steel for the construction of a 180,000-ton FPSO is about $360,000 \mathrm{~m}^{3}$. Considering the complete oxidation of acetylene to $\mathrm{CO}_{2}$ during steel cutting, the $\mathrm{CO}_{2}$ emission coefficient is $3.38 \mathrm{gCO}_{2} /$ (g acetylene), and the density of acetylene in the standard state is $1.17167 \mathrm{~kg} / \mathrm{m}^{3}$. The $\mathrm{CO}_{2}$ emission from FPSO cutting is $1425.7 \mathrm{t}$.

\subsection{Carbon Footprint of FPSO in the Operation phase}

\subsubsection{Input data}

\subsubsection{Energy demand}

The main energy needs of FPSO are shown in Fig. 4. This includes electrical energy, thermal energy, and cold energy. Three days, the 92nd day, the153th day and the 120th day, are chosen to represent summer, mid-season and winter.

It is easy to decipher that electricity is indispensable. From Fig. 4 (a) and (b), it can be seen that the water injection system consumes the most electricity in a year, and the total power consumption in winter is the most. For the whole system, because people on an FPSO unit 
require air conditioning and refrigeration to maintain normal lifestyle in summer, the demand for cooling energy decreases in winter and increases in summer, as shown in Fig. 4 (e). On the other hand, heating is needed in winter. The demand for heat energy decreases in summer and increases in winter, as shown in Fig. 4 (c) and (d).

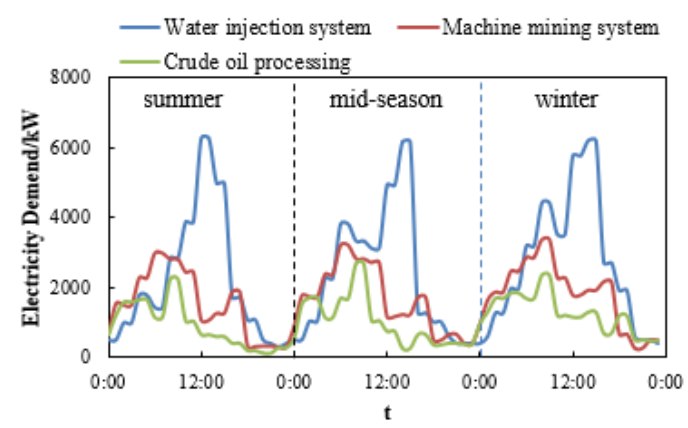

(a)

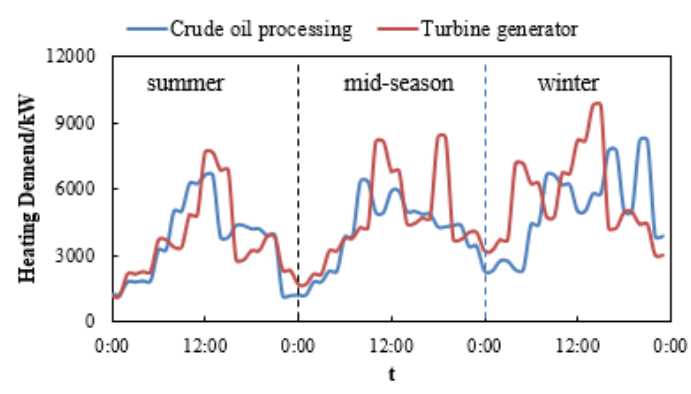

(c)

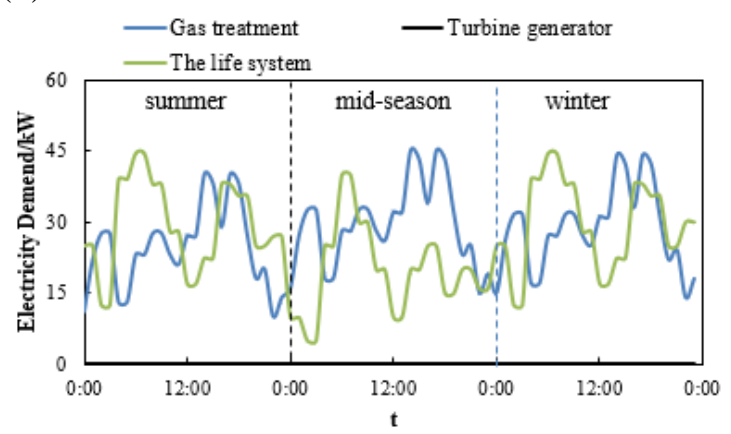

(b)

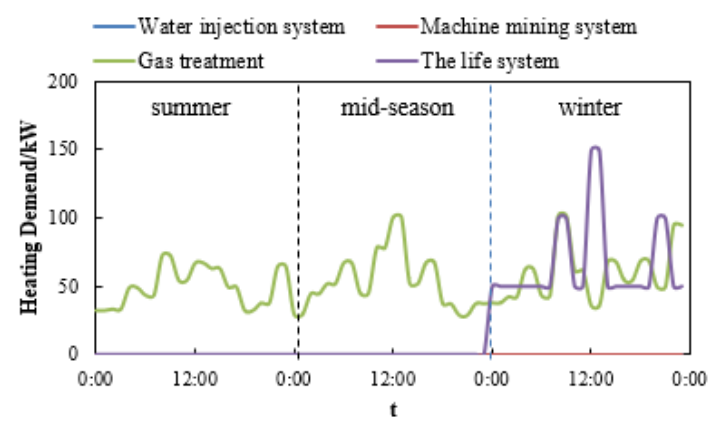

(d)

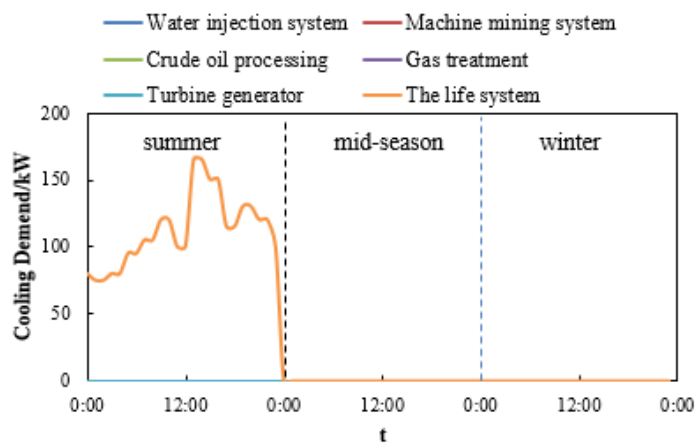

(e)

Fig. 4. (a,b) Electricity; (c.d) Heating; (e) Cooling demand for different systems at different periods on the FPSO.

\subsubsection{Solar radiation and wind power}

The model needs to input the weather information of solar and wind energy. The coastal area where the FPSO unit is located in a temperate marine climate. Westerly winds dominate the whole year, and the temperature in winter is relatively low. Combined with data acquisition, the solar radiation intensity of three typical days in this coastal area is estimated, as shown in Fig. 5. Wind power generation per unit area is mainly related to wind speed and air density. Fig. 6 shows the sea wind speed in this coastal area. It is obvious that the wind speed is high in winter and low in summer. The air density in winter is higher than that in summer. According to the above analysis, low air density and low wind speed in summer leads to low wind power and low power generation. 

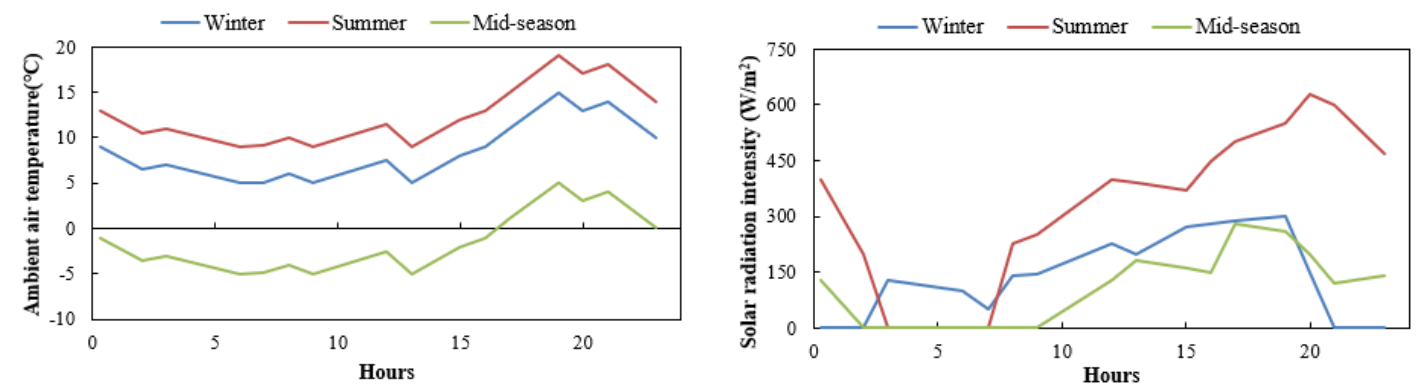

Fig. 5. Environmental temperature and solar radiation intensity in the Baltic Sea for three typical days.
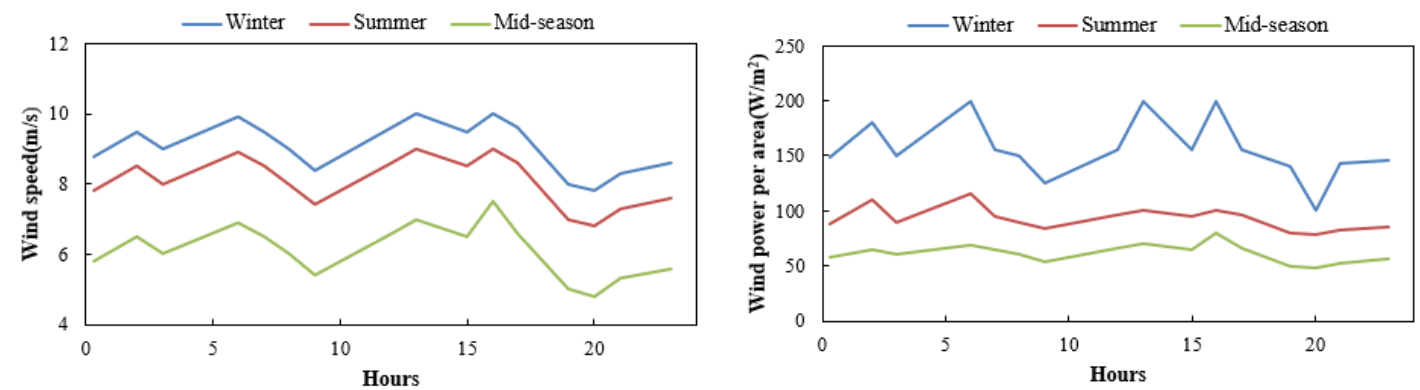

Fig. 6. Wind speed and wind power per area of the Baltic Sea on three typical days.

\subsubsection{Costs and emission factors of energy types}

Market data such as energy prices and equipment information are also important input parameters. Here, according to results from field investigation, the price of natural gas for Gas boiler and combustion turbine is constant $0.055 \mathrm{CHF} / \mathrm{kWh}$. Similarly, the price of crude oil is $0.0487 \mathrm{CHF} / \mathrm{kWh}$. Because an FPSO unit generally relies on its power supply, equipped with generators and transformers, this paper does not take electricity prices into account. The emission coefficients of crude oil and natural gas are $258 \mathrm{gCO}_{2} / \mathrm{kWh}$ and $198 \mathrm{gCO}_{2} / \mathrm{kWh}$, respectively. In addition, the interest rate is set at $8 \%$ to assess the total annual cost of DES.

\subsubsection{Technical and cost information on equipment}

The parameters of the DES equipment are shown in Table 1. These include the fixed cost, linear capacity-dependent cost, rated efficiency, and life span simultaneously the upper limit of the installed capacity of each equipment is listed. The size of the PV board is limited by the installation space while the operating efficiency of the equipment is set as a constant to maintain the linearity of the model.

Table 1 Parameters of the DES equipment.

\begin{tabular}{cccccc}
\hline Equipment & $\begin{array}{c}\text { Maximum } \\
\text { Capacity }(\mathrm{kW}, \\
\left.\mathrm{kWh}, \mathrm{m}^{2}\right)\end{array}$ & $\begin{array}{c}\text { Fixed } \\
\text { cost } \\
(\mathrm{CHF})\end{array}$ & $\begin{array}{c}\text { Linear cost of } \\
\text { equipment } \\
(\mathrm{CHF} / \mathrm{kW}, \mathrm{CHF} / \\
\left.\mathrm{kWh}, \mathrm{CHF} / \mathrm{m}^{2}\right)\end{array}$ & $\begin{array}{c}\text { Rated } \\
\text { efficiency/ } \\
\text { EER }\end{array}$ & Life (a) \\
\hline $\begin{array}{c}\text { Gas boiler } \\
\text { Gas turbine } \\
\text { engine }\end{array}$ & 20000 & 66100 & 200.0 & $87.50 \%$ & 25 \\
$\begin{array}{c}\text { Compression } \\
\text { Compon }\end{array}$ & 20000 & 69140 & 210.0 & $90.00 \%$ & 20 \\
\end{tabular}


chiller

\begin{tabular}{cccccc}
$\begin{array}{c}\text { Absorption } \\
\text { chiller }\end{array}$ & 20000 & 76015 & 230.0 & 1.45 & 20 \\
PV panels & 300 & 5750 & 290.0 & $15.00 \%$ & 20 \\
Wind Turbines & 200 & 5500 & 270.0 & $20.00 \%$ & 20 \\
$\begin{array}{c}\text { Crude oil } \\
\text { generator }\end{array}$ & 20000 & 86610 & 240.0 & $90.00 \%$ & 20 \\
Heat storage & 5000 & 1685 & 12.5 & $90.00 \%$ & 20 \\
Batteries & 5000 & 1685 & 12.5 & $90.00 \%$ & 20 \\
Cold storage & 5000 & 1685 & 12.5 & $90.00 \%$ & 20 \\
\hline
\end{tabular}

\subsubsection{Pareto frontier}

In this paper, there are 1393 constraints, 10 binary decision variables, and 1303 continuous decision variables. These data are tested, and the optimization problem can be solved in a few seconds. Fig. 7 shows the Pareto frontier. It can be seen from the graph that when point a $w=0$, only the optimization of environmental objectives is considered, when the total annual economic cost is $1.0720 \times 10^{7} \mathrm{CHF}$, and the carbon emission is $2.8651 \times 10^{4} \mathrm{t}$; When point $\mathrm{b} \mathrm{w}=1$ only the optimization of economic objectives is considered, when the total annual economic cost is $7.8627 \times 10^{6} \mathrm{CHF}$, and the carbon emission is $3.2812 \times 10^{4} \mathrm{t}$. The two extreme points are divided into 10 equal parts and then optimized separately. These 10 points correspond to 10 different DES design and operation schemes, providing designers with different references.

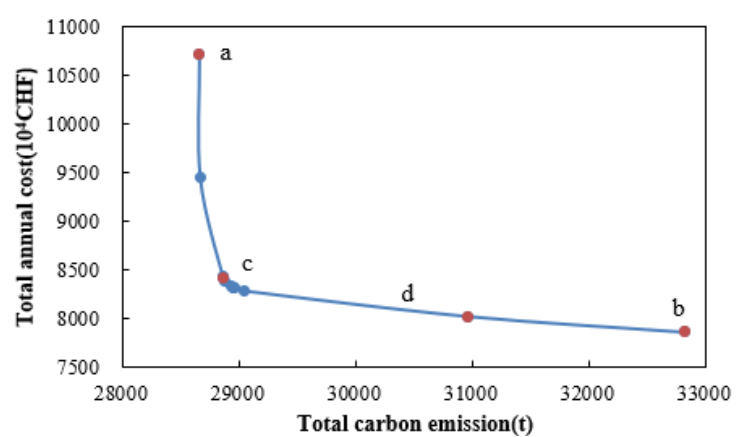

Fig. 7. The Pareto frontier obtained by weighing economic and environmental objectives is optimized separately.

\subsubsection{Optimized DES design scheme}

Four typical points are selected from the graph for analysis. The distribution scheme and installation capacity of the optimized distributed energy system are shown in Table 2.

Table 2 Optimized design scheme at Four typical points.

\begin{tabular}{ccccc}
\hline $\begin{array}{c}\text { Optimized } \\
\text { Solution }\end{array}$ & $\mathrm{a}$ & $\mathrm{c}$ & $\mathrm{d}$ & $\mathrm{b}$ \\
\hline Wind turbine & 200 & 200 & 0 & 0 \\
Gas boiler & 20000 & 11997 & 8632 & 10998 \\
Crude oil generator & 20000 & 6811 & 14533 & 18561
\end{tabular}




\begin{tabular}{|c|c|c|c|c|}
\hline Gas turbine engine & 20000 & 19874 & 6330 & 0 \\
\hline $\begin{array}{l}\text { Compression } \\
\text { chiller }\end{array}$ & 20000 & 72 & 35 & 35 \\
\hline Absorption chiller & 20000 & 0 & 0 & 0 \\
\hline PV panels & 300 & 300 & 0 & 0 \\
\hline Heat storage & 5000 & 5000 & 5000 & 5000 \\
\hline Batteries & 5000 & 0 & 0 & 0 \\
\hline Cold storage & 5000 & 1347 & 0 & 0 \\
\hline $\begin{array}{c}\text { Total annual cost } \\
(\mathrm{CHF})\end{array}$ & $1.07 \times 10^{7}$ & $8.42 \times 10^{6}$ & $8.03 \times 10^{6}$ & $7.86 \times 10^{6}$ \\
\hline $\begin{array}{l}\text { Total carbon } \\
\text { emission }(\mathrm{t})\end{array}$ & $2.87 \times 10^{4}$ & $2.89 \times 10^{7}$ & $3.09 \times 10^{7}$ & $3.28 \times 10^{4}$ \\
\hline
\end{tabular}

It can be seen from Table 2 that when $\mathrm{w}=0$, only the optimization of the environmental target is considered, and the capacity of each device reaches the maximum value, thus minimizing energy consumption. When $\mathrm{w}=1$, only the economic target is considered. At this time, the crude oil generator has replaced the gas turbine, indicating that the crude oil generator is more conducive to the realization of economic optimization objectives.

Combustion turbine and crude oil generator are the main sources of electricity and heat energy. Therefore, there is a certain relationship between the choice and application of the two. With the increase of $w$, the capacity of combustion turbine decreases, but the capacity of crude oil generators increases. This may be due to the fact that crude oil generators are superior to combustion turbine in power generation efficiency, which is more favorable for economic optimization. When the economic goal is optimal, $\mathrm{w}=1$, the power supply of the FPSO comes entirely from the crude oil generator. Although the equipment cost of the crude oil generator is higher than that of the gas turbine, it is negligible compared to the fuel cost.

Gas boiler is selected in four scenarios. With the increase of w, the boilers first increase and then decrease, but the capacity change is not very big, which is due to the fact that a lot of waste heat has been generated in the power generation process of combustion turbine and crude oil generators. Boilers are only used as a supplement to stabilize the heat supply.

The compression chiller was chosen for the cooling mode, not the absorption chiller since the FPSO unit has a lesser demand for cold energy, and it only needs to be provided in the summer. Although the excess heat of the FPSO can be used for absorption chillers, the fixed cost and operating cost of absorption chillers are very expensive. By contrast, it is the choice of compression refrigeration units that is economical and feasible as $\mathrm{w}$ increases, the capacity of the compression chiller continues to decrease and finally stabilizes at around $35 \mathrm{~kW}$.

Thermal storage equipment reaches maximum under all configurations, highlighting the role of peak cutting. The capacity of the battery is 0 because the ratio of electricity to heat is reasonable and there is no need to store electrical energy. As the economic goals increase, the cold storage capacity increases the load on the economy leading to little or no use for the cold storage facilities. The total capacity of energy storage equipment increases with the increase of environmental objectives. This result highlights the convenience of storage technology for environmental purposes, as it may reduce unnecessary energy losses.

The use of PV panels and wind turbines can effectively reduce environmental pollution, but the space for the FPSO unit is limited. Therefore, these two facilities will not be chosen 
under economic goals. This indicates that the development and utilization of solar and wind energy at sea are greatly limited.

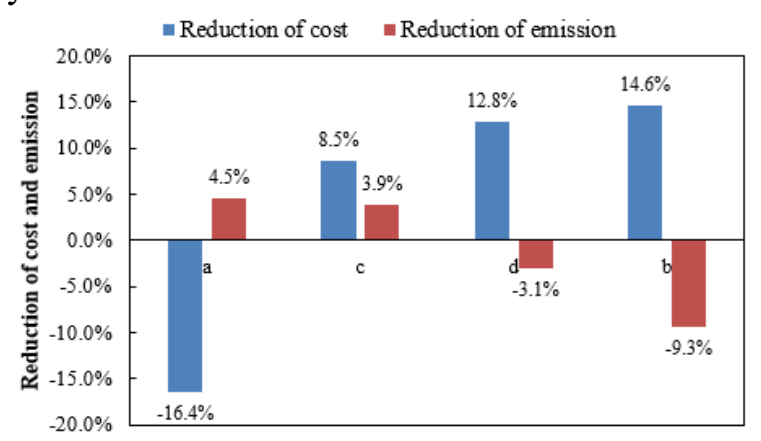

Fig. 8. Results of the economic and environmental comparison between four typical points and traditional programs.

In the traditional FPSO, electric energy is supplied by the gas turbine. The heat energy is provided by the gas boiler and the gas turbine. Cooling is provided by compression chiller. If only economic benefit is taken into account, the formulas (6), (7), and (8) in the third section model can be written as:

$$
\begin{gathered}
n_{G T, e l e} M_{t, G T}-M_{t, C C}=D_{t}^{e} \forall t \in T \\
E E R_{C C} M_{t, C C}=D_{t}^{c} \quad \forall t \in T \\
n_{G B, \text { heat }} M_{t, G B}+n_{G T, \text { heat }} M_{t, G T}=D_{t}^{h} \forall t \in T
\end{gathered}
$$

It can be obtained by using Matlab2014b the total annual cost of the FPSO under the traditional mode is $9.2 \times 10^{6} \mathrm{CHF}$, and the carbon emission is $3.0 \times 10^{4} \mathrm{t}$. As can be seen from Fig. 8 , the largest reduction in economic target optimization is $14.6 \%$, and the largest reduction in environmental targets is $4.53 \%$. At point $b$, the carbon emissions are $9.33 \%$ that is more than conventional scheme. The gas turbine is replaced by the crude oil generator, the consumption of natural gas is reduced, and the consumption of crude oil is increased, so the carbon emissions exceed the traditional situation.

With an FPSO operation life of 25 years, the FPSO's $\mathrm{CO}_{2}$ emissions under the environmental target for the entire operating cycle are 716,000 tons, and the $\mathrm{CO}_{2}$ emissions under the economic target are 820,000 tons.

\subsubsection{Operation strategies of energy devices under economic and Environment optimization}

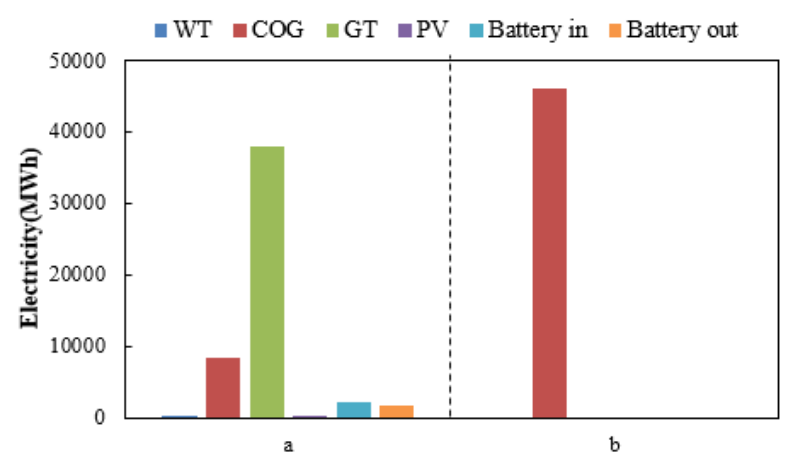

(a) 


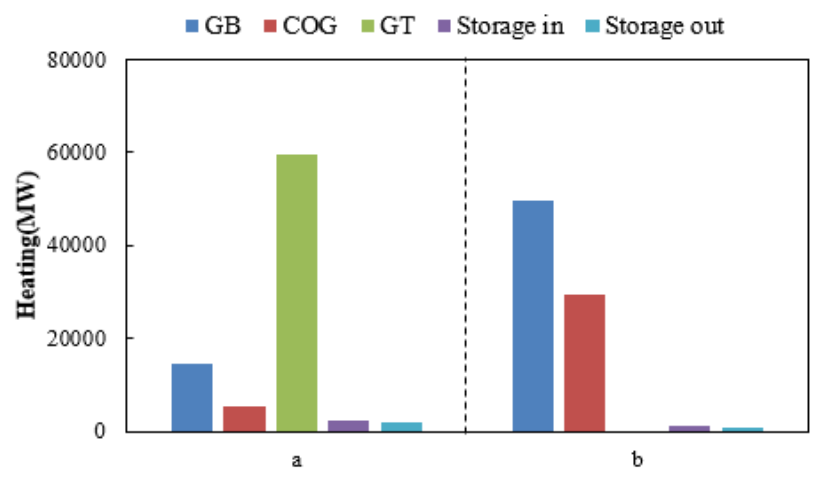

(b)

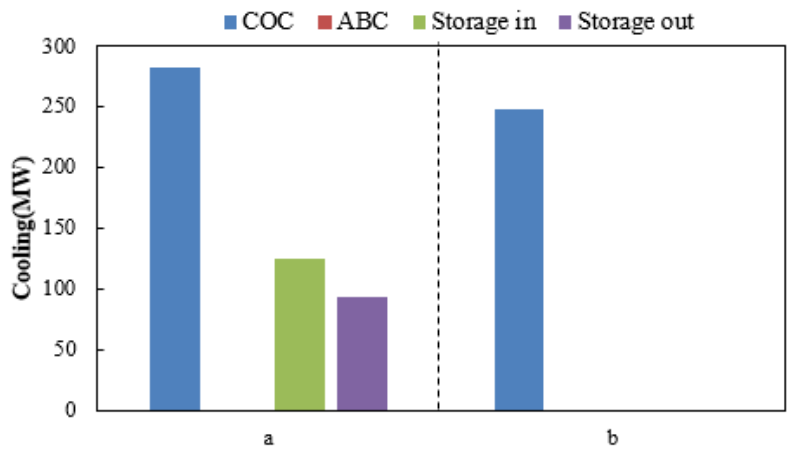

(c)

Fig. 9. Optimization of DES operation strategy at points a and b for (a) electricity; (b) heating; and (c) cooling.

Fig. 9 (a) shows the power supply of wind turbines, solar generators, combustion turbine and crude oil generators for an FPSO unit. It can be seen that the power generation of crude oil generators and combustion turbine far exceeds the supply of PV panels and wind turbines, indicating that the application of solar energy and wind energy in offshore platforms is still limited by too much space. At the point a of the environmental optimization goal, more than half of the FPSO's electrical energy comes from combustion turbine. Since the relatively low carbon emissions from burning natural gas, combustion turbine have an important impact on the environment. At point $b$ of the objective of economical optimization, all electrical energy on the FPSO comes from crude oil generators. The price of crude oil is relatively low so that crude oil generators play a decisive role in the economy. The total flow of batteries under environmental optimization is larger than that under economic optimization, which indicates that the capacity required under environmental optimization is larger.

Fig. 9 (b) shows the heat energy supplied by Gas boiler, crude oil generators and combustion turbine for FPSO under the conditions of economic and environmental optimization objectives. It is obvious that most of the heat energy under the environmental objectives comes from combustion turbine, which is related to their low carbon emissions from burning natural gas and providing more electricity. This highlights the importance of combustion turbine under environmental objectives. In terms of heat storage, because of the large quantity of exhaust gas, it is more commonly used in environmental optimization than in economic optimization. This is also the reason for the larger capacity required for environmental optimization.

Fig. 9 (c) shows the total cooling energy supplied by the compression chiller and the absorption chiller for FPSO. Under both objectives, the vast majority of them come from 
compression refrigeration units, which highlights the advantages and efficiency of the compression chiller.

\subsection{Carbon footprint of the FPSO disassembly phase}

$\mathrm{CO}_{2}$ emissions from the dismantling of FPSO are mainly $\mathrm{CO}_{2}$ emissions caused by steel cutting and power consumption in production. According to analogous estimation [53], when dismantling a 180,000-ton FPSO unit, assuming that the consumption of acetylene in cutting fuel gas is $500,000 \mathrm{~m}^{3}$ and the power consumption is 10,000 degrees, the $\mathrm{CO}_{2}$ emissions are $1980 \mathrm{t}$ and $10 \mathrm{t}$, respectively.

\subsection{Evaluation and analysis}

By analogy with the earlier research methods[54]: The impact of GHG emissions over the life cycle of various products is evaluated, and the $\mathrm{CO}_{2}$ equivalent impact of $\mathrm{GHG}$ emissions within 100 years after the product is formed should be evaluated. When all GHG emissions during the use phase occur within one year of the product formation, these emissions should be treated as a single emission at the beginning of the 100-year evaluation period. When emissions from the use phase are more than one year, a factor should be used to represent the weighted average time of existing emissions in the atmosphere during the 100 -year evaluation period. The weighting factor is calculated as follows:

$$
\text { Weighting coefficient }=\frac{\sum_{i=1}^{n} x_{i} \cdot(100-i)}{100}
$$

Where: $i$ represents the $i$ th year of carbon emissions and the life of the FPSO is 25 years; $x_{i}$ is the ratio of emissions in the $i$-year to total emissions, here taken as 0.04 . According to the above formula, the carbon emissions in the operation phase of the FPSO are amended, and the $\mathrm{CO}_{2}$ emissions in the life-cycle boundary of the FPSO are summarized after the amendment, as shown in Table 3.

Table $3 \mathrm{CO}_{2}$ Emissions from FPSO at Different Stages of Life Cycle.

\begin{tabular}{|c|c|c|c|c|c|}
\hline \multirow{2}{*}{$\begin{array}{c}\text { Carbon } \\
\text { Footprint of } \\
\text { FPSO/ } \\
\left(10^{4} \mathrm{t}\right)\end{array}$} & \multicolumn{3}{|c|}{ Construction phase } & \multirow[b]{2}{*}{$\begin{array}{l}\text { Operation } \\
\text { phase }\end{array}$} & \multirow[b]{2}{*}{$\begin{array}{c}\text { Dis- } \\
\text { assembly } \\
\text { phase }\end{array}$} \\
\hline & $\begin{array}{c}\text { Steel } \\
\text { processing } \\
\text { phase }\end{array}$ & $\begin{array}{c}\text { Steel } \\
\text { transportation } \\
\text { phase }\end{array}$ & $\begin{array}{c}\text { Construction } \\
\text { phase }\end{array}$ & & \\
\hline $\begin{array}{c}\text { Carbon } \\
\text { emissions }\end{array}$ & 6.6864 & 0.0095 & 1.3502 & 71.3400 & 0.1990 \\
\hline \multicolumn{6}{|c|}{$\begin{array}{l}\text { The total carbon dioxide equivalent emissions of the FPSO life cycle is } 736,000 \text { tons: The } \\
\text { on emission at the construction stage is } 8.5 \text { million tons, accounting for } 11.5 \% \text { of the total } \\
\text { on emissions in the whole life cycle. In the recovery stage, the carbon emissions generated } \\
\text { the recycling of raw materials are } 20,000 \text { tons, accounting for } 0.3 \% \text { of the total carbon } \\
\text { ssions in the whole life cycle. The carbon emissions in the operation stage are } 713000 \text { tons, } \\
\text { ounting for } 88.2 \% \text { of the total life cycle carbon emissions, which is the most important part } \\
\text { he FPSO life cycle carbon emissions. From the above data, although a large amount of } \\
\text { on emissions were generated during the construction phase, the construction phase only } \\
\text { upies a very small proportion of carbon emissions compared with the huge carbon emissions }\end{array}$} \\
\hline
\end{tabular}


generated in the operation phase of 25 years. However, even though the carbon emissions generated during the construction and recovery stages are relatively small, the absolute emission value cannot be underestimated. At the same time, for a complete environmental assessment, it is negligible for the construction stage and the recycling stage.

In summary, to reduce carbon emissions throughout the life of the FPSO, it is necessary to control the carbon emitted by the FPSO operation process strictly. $\mathrm{CO}_{2}$ emissions from FPSO during operation are mainly caused by fuel combustion. Therefore, reducing fuel consumption during FPSO operation has become an important way to reduce the carbon footprint of FPSO throughout its life cycle. This requires the adoption of new energy-saving technologies and measures of FPSO. And the application of a distributed energy system can satisfy this demand well.

\subsection{Sensitivity analysis}

\subsubsection{The sensitivity of Crude oil Price under Economic Optimization Target}

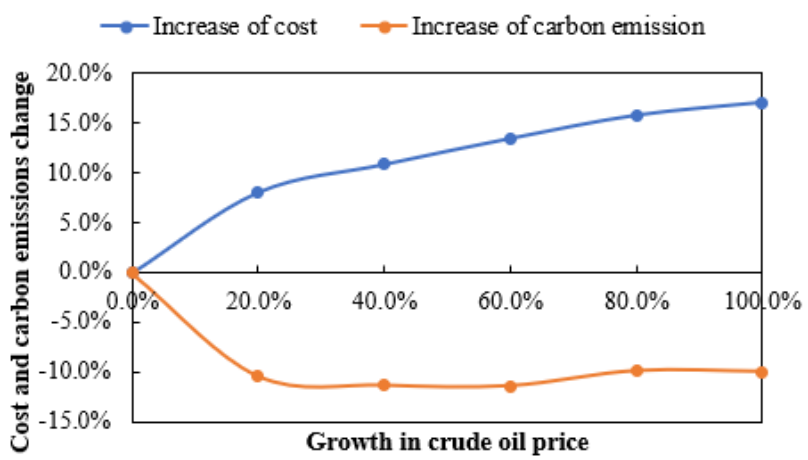

Fig. 10. Economic and Environmental Performance of Rising Crude oil Price under Economic Optimization Target.

Fig. 10 is a graph showing the economic and environmental benefits of crude oil prices rising from $20 \%$ to $100 \%$ under the conditions of economic optimization. The rise in crude oil prices has led to a reduction in crude oil consumption and an increase in natural gas consumption. Therefore, the environmental benefits of carbon emissions have decreased.

For ease of observation, Table 4 shows the equipment capacity allocation for each crude oil price growth rate. It can be seen that the increasing price of crude oil gradually reflects the advantages of solar panels. The capacity of the compression chiller is unchanged due to the low investment price of energy. With the rising price of crude oil, the advantages of combustion turbine are reflected. Capacity increases until it gets to the maximum.

Table 4 The total capacity of DES for various Crude oil price increases.

\begin{tabular}{ccccccccccc}
\hline & WT & GB & COG & GT & CC & AC & PV & HS & BT & CS \\
\hline 0 & 0 & 10998 & 18561 & 0 & 35 & 0 & 0 & 5000 & 0 & 0 \\
$20 \%$ & 0 & 7386 & 6856 & 18393 & 31 & 0 & 0 & 5000 & 0 & 33 \\
$40 \%$ & 0 & 7386 & 6856 & 18393 & 31 & 0 & 0 & 5000 & 0 & 33 \\
$60 \%$ & 0 & 7497 & 6371 & 19156 & 31 & 0 & 0 & 5000 & 0 & 33 \\
$80 \%$ & 0 & 7497 & 5834 & 20000 & 31 & 0 & 0 & 5000 & 0 & 192 \\
$100 \%$ & 0 & 7504 & 5818 & 20000 & 36 & 0 & 300 & 5000 & 0 & 353 \\
\hline
\end{tabular}




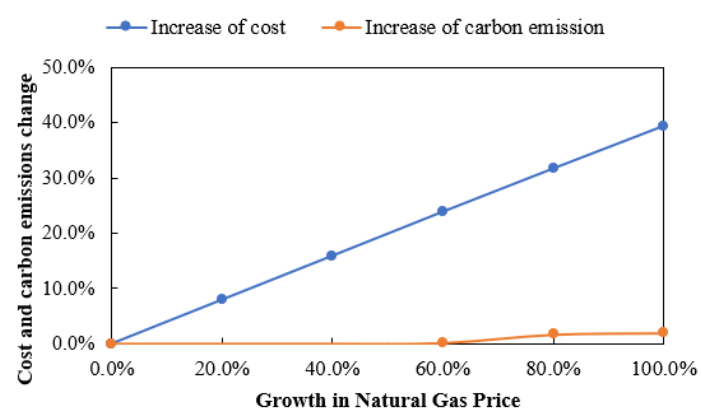

Fig. 11. Economic and Environmental Performance of Rising Natural Gas Price under Economic Optimizing Target.

FPSO has the capacity for natural gas storage and export. The surplus natural gas can be exported and sold as FPSO products. This hypothesis was put forward at the beginning of this paper. Fig. 11 shows the economic and environmental benefits of natural gas prices rising from $20 \%$ to $100 \%$. As can be seen from the Figure, the impact of natural gas prices on the economy is higher than that of crude oil price fluctuations, but the influence on environment is lower than that of crude oil price. When the price of natural gas tripled, the total annual cost increases by $40 \%$, and when the price of crude oil tripled, the total annual cost increases by less than $20 \%$, indicating the important role of natural gas in the supply of the energy system. In terms of environmental benefits, increasing the price of natural gas to $60 \%$ would reduce carbon emissions.

For ease of observation, Table 5 shows the equipment capacity allocation for each natural gas price growth rate. It is clear that with the rise in the price of natural gas, the capacity of each device changes by a small margin due to the peaking effect of thermal energy storage equipment. As a result, fuel consumption and carbon emissions are basically unchanged, and economic growth is due to the increase in fuel costs.

Table 5 The total capacity of DESs for various natural gas price increases.

\begin{tabular}{ccccccccccc}
\hline & WT & GB & COG & GT & CC & AC & PV & HS & BT & CS \\
\hline 0 & 0 & 10998 & 18561 & 0 & 35 & 0 & 0 & 5000 & 0 & 0 \\
$20 \%$ & 0 & 10998 & 18561 & 0 & 35 & 0 & 0 & 5000 & 0 & 0 \\
$40 \%$ & 0 & 11000 & 18561 & 0 & 35 & 0 & 0 & 4997 & 0 & 0 \\
$60 \%$ & 0 & 11000 & 18561 & 0 & 35 & 0 & 0 & 4096 & 0 & 0 \\
$80 \%$ & 0 & 10778 & 18561 & 0 & 35 & 0 & 0 & 0 & 0 & 0 \\
$100 \%$ & 0 & 10471 & 18561 & 0 & 35 & 0 & 0 & 535 & 0 & 0 \\
\hline
\end{tabular}

\section{Conclusions}

In this paper, the source of Floating Production Storage and Offloading carbon footprint is discussed with the life cycle as the time axis. Which is crucial for the carbon footprint reduction from the entire supply chain of Floating Production Storage and Offloading. It was discovered that Floating Production Storage and Offloading is a conceptual product at the design stage and does not have the economic activity that produces carbon footprint; The source of carbon footprint in the construction stage is from production, transportation of steel and the 
construction process of the Floating Production Storage and Offloading unit. The carbon footprint of the operational phase is represented by the energy consumption of the Floating Production Storage and Offloading when it operates at sea; At the dismantling stage, the Floating Production Storage and Offloading unit have been laid-up entering the dismantling stage, recovering some equipment and resources, and generating carbon emissions. Taking a Pacific Floating Production Storage and Offloading unit as an example, the carbon emissions of different stages of Floating Production Storage and Offloading are calculated. The results show that the carbon footprint of Floating Production Storage and Offloading accounts for the largest proportion in the operation stage.

For the operation stage, this paper is to develop a multi-objective optimization model by introducing a distributed energy system on the Floating Production Storage and Offloading to determine the combination of equipment types and capacities on the Floating Production Storage and Offloading. This reduces the system's economic costs and carbon emissions. In this paper, the economic objective function and carbon emission objective function are established. In order to minimize the two objective functions, a single objective function is used to express the weights of total economic cost and total carbon emissions, and the minimum value of the single objective function is obtained. Pareto boundaries can be found by changing weights and switching them between 0 and 1. This model can be applied to the actual Floating Production Storage and Offloading unit. By inputting the corresponding energy demand, different equipment combination schemes can be obtained to provide planners with different selection strategies.

The research shows that the distributed energy system can reduce the total cost by $14.6 \%$ and the carbon emission can be reduced by $1360 \mathrm{t}$ as compared with the traditional scheme through a reasonable and optimized design. At the same time, sensitivity analysis is carried out to analyze the impact on the economy and carbon emissions when the price of crude oil and natural gas fluctuates. The results show that the increase in natural gas prices is greater than the increase in crude oil prices for the optimized distributed energy system configuration and economics.

\section{Nomenclature}

Sets and indices
$i \in I \quad$ All equipment: WT, GB, COG, GT, CC, AC, PV, HS, BT, CS
$j \in J \quad$ Energy allocation equipment: WT, GB, COG, GT, CC, AC
$k \in K \quad$ Energy storage equipment: HS, BT, CS
$m \in M \quad$ Energy types: oil, gas
$t \in T \quad$ Time steps
$t \in \bar{T} \quad$ First time step of the day
Continuous Parameters
$P V \quad$ Available capacity for PV panels [kWh]
$S_{k}^{M A X} \quad$ Maximum capacity for energy storage equipment $k \quad[\mathrm{kWh}]$
$S_{P V}^{r o o f} \quad$ Available desk area for installation of PV panels on FPSO $\left[\mathrm{m}^{2}\right]$ 
$S_{W T}^{\text {roof }} \quad$ Available desk area for installation of WT on FPSO $\left[\mathrm{m}^{2}\right]$

$E_{i} \quad$ Fixed cost of equipment $i[\mathrm{CHF}]$

$F_{i} \quad$ Linear cost of equipment $i$ installation $\left[\mathrm{CHF} / \mathrm{kW}, \mathrm{CHF} / \mathrm{kWh}, \mathrm{CHF} / \mathrm{m}^{2}\right]$

MAX The Maximum capacity of equipment [kWh]

MIN The Minimum capacity of equipment [kWh]

$n_{k}^{c h} \quad$ Charging efficiency of energy storage equipment $k \quad[-]$

$n_{k}^{\text {dis }} \quad$ Discharging efficiency of energy storage equipment $k[-]$

$n_{k}^{\text {loss }} \quad$ Self-discharge losses of energy storage equipment $k \quad[-]$

$L t_{i} \quad$ Service life of energy storage equipment $i$ [years]

$n_{i} \quad$ Conversion efficiency of equipment $i \quad[-]$

$r \quad$ Discount rate [-]

$w_{t} \quad$ The number of time step $t$ in a typical day [-]

$P_{t, m} \quad$ Price of energy types $m$ at time $t$ [CHF/kWh]

$E F_{m} \quad$ Carbon emissions of the energy type $m\left[\mathrm{gCO}_{2} / \mathrm{kWh}\right]$

$I N_{t}^{P V} \quad$ The amount of solar energy input in time $t\left[\mathrm{kWh} / \mathrm{m}^{2}\right]$

$I N_{t}^{W T} \quad$ The amount of wind energy input in time $t\left[\mathrm{kWh} / \mathrm{m}^{2}\right]$

$D_{t}^{e} \quad$ Electricity demand at time step $t[\mathrm{kWh}]$

$D_{t}^{h} \quad$ Heating demand at time step $t[\mathrm{kWh}]$

$D_{t}^{c} \quad$ Cooling demand at time step $t[\mathrm{kWh}]$

$c \quad c$ is the scale factor [-]

Positive continuous variables

$W_{i} \quad$ Capacity of equipment $i\left[\mathrm{~kW}, \mathrm{kWh}, \mathrm{m}^{2}\right]$

$C P_{t, m} \quad$ Consumption of energy type $m$ at time step $t[\mathrm{kWh}]$

$M_{t, i} \quad$ Energy input to the converter $i$ at time step $t[\mathrm{kWh}]$

$N_{t, k}^{c h} \quad$ Charging rate of energy storage equipment $k$ at time step $t$ [kWh]

$N_{t, k}^{d i s} \quad$ Discharging rate of energy storage equipment $k$ at time step $t$ [kWh]

$S_{t, k} \quad$ Energy stored in equipment $k$ at time step $t[\mathrm{kWh}]$

Binary variables

$B_{i} \quad$ If the equipment $\mathrm{i}$ is selected $B_{i}=1$. Otherwise, $B_{i}=0$

Acronyms

DES Distributed Energy System

MOMP Multi-objective Mathematical Programming

WT Wind Turbine

GB Gas Boiler 


$\begin{array}{ll}\text { GT } & \text { Gas Turbine } \\ \text { COG } & \text { Crude Oil Generator } \\ \text { CC } & \text { Compression Chiller } \\ \text { AC } & \text { Absorption Chiller } \\ \text { PV } & \text { PV panels } \\ \text { BT } & \text { Battery } \\ \text { HS } & \text { Heat Storage } \\ \text { CS } & \text { Cold Storage }\end{array}$

\section{Acknowledgement}

This work was partially supported by the National Natural Science Foundation of China (51874325), the decision system for optimization of offshore engineering mode (2016zx0503004-004) from the National Science and technology major project, and the Grantin-Aid for Early-Career Scientists (19K15260) from the Japan Ministry of Education, Culture, Sports, Science and Technology. The authors are grateful to all study participants.

\section{References}

[1] Lei Wu, Yaowen Yang, Muneesh Maheshwari, Ning Li. Parameter optimization for FPSO design using an improved FOA and IFOA-BP neural network[J]. Ocean Engineering,2019,175.

[2] Mohammad Saidee Hasan. A Simplified Method for Analyzing the Fatigue life of a FPSO Mooring System[J]. Procedia Engineering,2017,194.

[3] Buhaug, Corbett J J, Endresen. Second IMO GHG study, 2009[R]. International Maritime Organization (IMO), London, 2009.

[4] Lindstad H, Asbjørnslett B E, Strømman A H. Reductions in greenhouse gas emissions and cost by shipping at lower speeds[J]. Energy Policy, 2011, 39(6): 3456-3464.

[5] Guan D., Meng J., Reiner D.M. Structural decline in China's $\mathrm{CO}_{2}$ emissions through transitions in industry and energy systems. Nature Geosci 11, 551-555 (2018) doi:10.1038/s41561-018-0161-1.

[6] Jia Shuo Li, H.W. Zhou, Jing Meng, Q. Yang, B. Chen, Y.Y. Zhang. Carbon emissions and their drivers for a typical urban economy from multiple perspectives: A case analysis for Beijing city[J]. Applied Energy,2018,226.

[7] Chen B., Li J. S., Wu X. F., Han, M. Y., Zeng, L., Li, Z., Chen, G. Q., Global energy flows embodied in international trade: A combination of environmentally extended inputoutput analysis and complex network analysis. Applied Energy, 2018. 210: p. 98-107.

[8] Fang K, Zhang Q, Long Y, Yoshida Y, Sun L, Zhang H, Dou Y, Li S. How can China achieve its Intended Nationally Determined Contributions by 2030? A multi-criteria allocation of China's carbon emission allowance. Applied Energy, 2019, 241: 380-389.

[9] Kai Fang, Yiqi Tang, Qifeng Zhang, Junnian Song, Qi Wen, Huaping Sun, Chenyang Ji, Anqi Xu. Will China peak its energy-related carbon emissions by 2030? Lessons from 30 Chinese provinces[J]. Applied Energy,2019,255.

[10] Hui Qiao, Siyu Chen, Xiucheng Dong, Kangyin Dong,2019. Has China's coal consumption actually reached its peak? National and regional analysis considering crosssectional dependence and heterogeneity. Energy Economics 2019, 104509. https://doi.org/10.1016/j.eneco.2019.104509.

[11] Hui Qiao, Fengtian Zheng, Hongdian Jiang, Dong Kangyin. The greenhouse effect of the agriculture-economic growth-renewable energy nexus: Evidence from G20 countries.[J]. The Science of the total environment,2019,671.

[12] Kangyin Dong, Xiucheng Dong \& Cong Dong (2019) Determinants of the global and 
regional $\mathrm{CO}_{2}$ emissions: What causes what and where?, Applied Economics, 51:46, 5031-5044, DOI: $10.1080 / 00036846.2019 .1606410$

[13] Roberta Quadrelli, Sierra Peterson. The energy-climate challenge: Recent trends in $\mathrm{CO}_{2}$ emissions from fuel combustion[J]. Energy Policy,2007,(35):5938-5952

[14] DEAN J. Pricing policies for new Products [J]. Harvard Business Review.1950,28(6):45-53

[15] Tommy Johnsen, Annik Magerholm Fet. Screening Life Cycle Assessment of M/V Color Festival, Research report HiA 10/B101/R-98/009/00, Aalesund College(HiA)in cooperation with Det Norske Veritas(DNV),1999

[16] H.Ellingsen, A.M.Fet, and S.Aanondsen. Tool for Environmental Efficient Ship Design[J],ENSUS 2002,Newcastle,UK,2002

[17] Michihihiro KAMEYAMA. Life cycle inventory analysis of $\mathrm{CO}_{2}$ emission from ship, Proceeding of the 4th International Conference on EcoBalance,2000[C].517 520

[18] RINK D R, SWAN JE. Product life cycle research: a literature review[J].Journal of Business Research.1979,7(3):219-242

[19] Sulaiman, O., A. H. Saharuddin, and A. S. A. Kader. Towards sustainable green ship technology. African Journal of Business Management 7.2 (2013): 96-118

[20] Okasha N M, Frangopol D M, Decò A. Integration of structural health monitoring in life- cycle performance assessment of ship structures under uncertainty[J]. Marine Structures, 2010, 23(3): 303-321

[21] Frangopol D M, Bocchini P, Decò A. Life-cycle ship reliability assessment, damage detection, and optimization[C]//Proceedings of the 11th International Conference on Fast Sea Transportation-FAST 2011. 2011: 26-29

[22] Kumakura Y, Sasajima H. A consideration of Life Cycle Cost of a Ship[C]//Proceedings of the Eighth International Symposium on Practical Design of Ships and Other Floating Structures. 2001: 29-35

[23] Misra S C. Sustainable Development And Ship Life Cycle[J]. International Journal of Innovative Research and Development, 2012, 1(10): 112-120

[24] Erik.Ranheim. Shipping and the Environment GHG Emissions from Ships the Industry's Perspective. The European Maritime Day. Cyprus 2009

[25] Eyring V, Köhler H W, Van Aardenne J. Emissions from international shipping: 1. The Last 50 years[J].Journal of Geophysical Research: Atmospheres (1984 - 2012),2005,110 (D17)

[26] Tuong-Van Nguyena, MariVoldsund, PeterBreuhausc, BrianElmegaarda. Energy efficiency measures for offshore oil and gas platforms. Energy, 2016. 117: p. 325-340.

[27] Ali Allahyarzadeh-Bidgoli, Leandro Oliveira Salviano, Daniel Jonas Dezan. Energy optimization of an FPSO operating in the Brazilian Pre-salt region. Energy, 2018. 164: p. 390399.

[28] J.S. Li, X.H. Xia, G.Q. Chen, A. Alsaedi, T. Hayat. Optimal embodied energy abatement strategy for Beijing economy: Based on a three-scale input-output analysis[J]. Renewable and Sustainable Energy Reviews,2016,53.

[29] De Oliveira, S. and M. Van Hombeeck. Exergy analysis of petroleum separation processes in offshore platforms. Energy Conversion and Management, 1997. 38(15): p. 15771584.

[30] Tuong-Van Nguyen, Tomasz Jacyno, Peter Breuhaus, Mari Voldsund, Brian Elmegaard. Thermodynamic analysis of an upstream petroleum plant operated on a mature field. Energy, 2014. 68: p. 454-469.

[31] Tingjun Yan, Xuhe Zhao, Xiaohe Wang, Jifei Yu, Yifan Shi. Study on energy conservation water injection system of offshore platform based on jet pump. Journal of Petroleum Science and Engineering, 2018. 170: p. 368-373.

[32] Mari Voldsund, Tuong-Van Nguyen, Brian Elmegaard, Ivar S. Ertesvåg, Signe Kjelstrup. Exergy destruction and losses on four North Sea offshore platforms: A comparative study of the oil and gas processing plants. Energy, 2014. 74: p. 45-58.

[33] Tuong-Van Nguyen, Tamás Gábor Fülöp, Peter Breuhaus, Brian Elmegaard. Life performance of oil and gas platforms: Site integration and thermodynamic evaluation. Energy, 2014. 73: p. 282-301. 
[34] Ezah Abdul Aziz, Sharifah Rafidah Wan Alwi, Jeng Shiun Lim, Zainuddin Abdul Manan, Jiří Jaromír Klemeš. An integrated Pinch Analysis framework for low $\mathrm{CO}_{2}$ emissions industrial site planning. Journal of Cleaner Production, 2017. 146: p. 125-138.

[35] Waldyr L.R. Gallo, Antonio G. Gallego, Victor L. Acevedo, Rodrigo Dias, Hamilton Y. Ortiz, Bruno A. Valente. Exergy analysis of the compression systems and its prime movers for a FPSO unit. Journal of Natural Gas Science and Engineering, 2017. 44: p. 287-298.

[36] Thiago Gotelip Correa Veloso, César Adolfo Rodriguez Sotomonte, Christian J. R. Coronado, Marco A. R. Nascimento. Multi-objective optimization and exergetic analysis of a low-grade waste heat recovery ORC application on a Brazilian FPSO. Energy Conversion and Management, 2018. 174: p. 537-551.

[37] Nord, L.O. and O. Bolland, Design and off-design simulations of combined cycles for offshore oil and gas installations. Applied Thermal Engineering, 2013. 54(1): p. 85-91.

[38] L. Pierobon, A. Benato, E. Scolari, F. Haglind, A. Stoppato, Waste heat recovery equipment for offshore platforms. Applied Energy, 2014. 136: p. 228-241.[30] Barrera, J.E., E. Bazzo, and E. Kami, Exergy analysis and energy improvement of a Brazilian floating oil platform using Organic Rankine Cycles. Energy, 2015. 88: p. 67-79.

[39] Fichera, A., M. Frasca, and R. Volpe, Complex networks for the integration of distributed energy systems in urban areas. Applied Energy, 2017. 193: p. 336-345.

[40] Sergio M. Camporeale, Antonio M. Pantaleo, Patrizia D. Ciliberti, Bernardo Fortunato. Cycle configuration analysis and techno-economic sensitivity of biomass externally fired gas turbine with bottoming ORC. Energy Conversion and Management, 2015. 105: p. 1239-1250.

[41] Luca Cioccolanti, Roberto Tascioni, Enrico Bocci, Mauro Villarini. Parametric analysis of a solar Organic Rankine Cycle trigeneration system for residential applications. Energy Conversion and Management, 2018. 163: p. 407-419.

[42] Maria E. Mondejar, Fredrik Ahlgren, Marcus Thern, Magnus Genrup. Quasi-steady state simulation of an organic Rankine cycle for waste heat recovery in a passenger vessel. Applied Energy, 2017. 185: p. 1324-1335.

[43] Suárez de la Fuente, S., D. Roberge, and A.R. Greig, Safety and $\mathrm{CO}_{2}$ emissions: Implications of using organic fluids in a ship's waste heat recovery system. Marine Policy, 2017. 75: p. 191-203.

[44] Leonardo Pierobon, Tuong-Van Nguyen, Ulrik Larsen, Fredrik Haglind, Brian Elmegaard. Multi-objective optimization of organic Rankine cycles for waste heat recovery: Application in an offshore platform. Energy, 2013. 58: p. 538-549.

[45] Harald Taxt Walnum, Petter Nekså, Lars O. Nord, Trond Andresen. Modeling and simulation of $\mathrm{CO}_{2}$ (carbon dioxide) bottoming cycles for offshore oil and gas installations at design and off-design conditions. Energy, 2013. 59: p. 513-520.

[46] Ren, H. and W. Gao, A MILP model for integrated plan and evaluation of distributed energy systems. Applied Energy, 2010. 87(3): p. 1001-1014.

[47] Jiajia Gao, Jing Kang, Chong Zhang, Wenjie Gang. Energy performance and operation characteristics of distributed energy systems with district cooling systems in subtropical areas under different control strategies. Energy, 2018. 153: p. 849-860.

[48] Yamin Yan, Haoran Zhang, Jing Meng, Yin Long, Xingyuan Zhou, Zhuochao Li, Yufei Wang, Yongtu Liang. Carbon footprint in building distributed energy system: An optimization-based feasibility analysis for potential emission reduction[J]. Journal of Cleaner Production,2019,239.

[49] Yamin Yan, Haoran Zhang, Yin Long, Yufei Wang, Yongtu Liang, Xuan Song, James J.Q. Yu. Multi-objective design optimization of combined cooling, heating and power system for cruise ship application[J]. Journal of Cleaner Production,2019,233.

[50] M. Di Somma, B. Yan, N. Bianco, G. Graditi, P.B. Luh, L. Mongibello, V. Naso. Multi-objective design optimization of distributed energy systems through cost and exergy assessments. Applied Energy, 2017. 204: p. 1299-1316.

[51] Paul W. Griffin, Geoffrey P. Hammond. Analysis of the potential for energy demand and carbon emissions reduction in the iron and steel sector[J]. Energy Procedia,2019,158.

[52] Malin Song, Guijun Zhang, Wuxiong Zeng, Jianhua Liu, Kuangnan Fang. Railway 
transportation and environmental efficiency in China[J]. Transportation Research Part $\mathrm{D}, 2016,48$.

[53] Duc Tuan Dong, Wei Cai. A comparative study of life cycle assessment of a Panamax bulk carrier in consideration of lightship weight[J]. Ocean Engineering,2019,172.

[54] Khoa N. Le, Cuong N.N. Tran, Vivian W.Y. Tam. Life-cycle greenhouse-gas emissions assessment: An Australian commercial building perspective[J]. Journal of Cleaner Production,2018,199. 